\title{
Growth in renal failure: a longitudinal study of emotional and behavioural changes during trials of growth hormone treatment
}

\author{
R J Postlethwaite, D M Eminson, J M Reynolds, A J Wood, S Hollis
}

\begin{abstract}
Growth and psychological functioning were studied in 30 patients with renal failure over a two year period following the offer of growth hormone treatment for significant short stature. Parents' concerns about growth decreased significantly during the study. Twenty eight parents $(93 \%)$ accepted growth hormone treatment; most $(74 \%)$ were satisfied with it and would opt for it again (89\%). The views of these parents were unrelated to growth outcome in their child. This suggests that the positive responses were related more to the effort to improve growth than to any objective treatment success. In contrast children's reduction in concern about growth, satisfaction with treatment $(36 \%)$, and decision to opt for growth hormone again $(50 \%)$ were all significantly related to improvement in growth. Parents' reports of noncompliance increased significantly from $41 \%$ at 1 year to $91 \%$ at 2 years in the group as a whole. No significant changes were identified in maternal mental distress and no additional costs to the psychological health of the children seem to have resulted from the introduction of growth hormone treatment. A group of children was identified who accepted treatment but had continued poor growth. These appeared to be at particular risk of both physical problems and associated or consequent psychological difficulties. (Arch Dis Child 1998;78:222-229)
\end{abstract}

Keywords: short stature; chronic renal failure; growth hormone; psychological problems

Growth retardation is a common result of chronic renal failure in childhood. ${ }^{12}$ The demonstration that supraphysiological doses of growth hormone could improve growth in uraemic rats $^{3}$ led to studies of growth hormone treatment in children with chronic renal failure. ${ }^{4-11}$ In general a beneficial growth response to growth hormone treatment has been found.

The psychological consequences of growth hormone treatment in renal failure have been little studied. Children without renal failure treated with growth hormone may improve ${ }^{12}$ or deteriorate ${ }^{13}{ }^{14}$ in behaviour, and children with pituitary growth hormone deficiency may be disappointed or have a poor psychological outcome when treatment does not promote the hoped for growth. ${ }^{15}$ The issue deserves particular consideration when use of growth hormone is contemplated in the course of an illness such as renal failure, which already makes heavy treatment demands on children and families. Sinnema et al examined 20 adolescents with a kidney transplant who were treated with growth hormone over a two year period. They responded well and reported minor (nonsignificant) improvements in measures of psychological health. ${ }^{16}$

We have previously reported that short stature is not the major concern of children with renal failure or their parents. ${ }^{17} 18$ Our clinical experience of using growth hormone in individual children was that it heightened concerns about growth and, because growth was less than hoped for, caused considerable distress for children and their parents. Trials of growth hormone treatment in renal failure afforded an opportunity to study this important issue further.

The study we report here was designed to test the hypothesis that introduction of growth hormone treatment in renal failure would increase concerns about growth in both parents and children, and lead to increased psychological problems. Concerns of the children and their parents at the outset of this study have already been reported. ${ }^{19}$ We now report the findings of a two year longitudinal study of emotional and behavioural changes during the course of trials of growth hormone treatment in predialysis, dialysis, and transplant patients. As we were studying the impact of discussing the possibility of improving their growth, we included children who received growth hormone, whether or not their growth improved, as well as those who declined the treatment. All children were therefore studied over the two year period. We also report the changes in parents' and children's concerns about growth, and their responses to the outcome of treatment.

\section{Methods}

PATIENT GROUP

Recruitment to this study, parental and child concerns about chronic renal failure and its treatment, and psychological and social adjustment at the start of this study have been reported previously. ${ }^{19}{ }^{20}$ We considered it essential, for ethical and psychological reasons, that the children and their parents understood both the anticipated increase in growth as a result of treatment and the possible adverse effects of treatment. We therefore paid attention at the 
outset to the information needs of the children and their parents. ${ }^{20}$

The 30 patients from four centres were all eligible for entry into the trials of growth hormone in renal failure. Their height was more than two standard deviations below mean for age or their height velocity was below the 25 th centile for age, or both. They had severe chronic renal failure or were on dialysis, or had a functioning renal transplant. Their age range was 2 to 19 years (mean 10.6 years). There were 24 males and six females.

PHYSICAL DATA

Detailed contemporary records were made of growth, growth hormone treatment and its side effects, and changes in renal treatment. Height is expressed as a height standard deviation score (SDS) calculated by the formula:

\section{Measured height - mean height for age Height standard deviation for age}

This allows for the heights of children of different ages to be compared directly. Changes in height are expressed as $\triangle$ SDS (SDS at two years minus SDS at entry). A positive value of the $\triangle$ SDS indicates above average (catch up) growth and a negative value below average growth (falling down the centiles). Good growth was defined as $\Delta S D S>1.0$, moderate growth as $\Delta$ SDS $>0 \leqslant 1$, poor growth as $\Delta \mathrm{SDS} \leqslant 0$.

\section{PSYCHOLOGICAL DATA}

\section{Questionnaires}

Screening measures were used at entry and two years to examine parents' reports of their children's behaviour, the children's own reports of their mood and self esteem, and parental mental distress. Parents of children under 7 years of age completed the Richman behaviour checklist $(\mathrm{BCL})^{21}$ and those of children aged 7 years and over completed the parents' behavioural screening questionnaire (Rutter " $\mathrm{A}$ "). ${ }^{22}$ Children completed the moods and feelings questionnaire (MFQ), ${ }^{23}$ which has been used in population samples in this age group to screen for depression, and the Harter perceived competence scale, ${ }^{25}{ }^{26}$ which examines several dimensions of self concept, producing four subscales of self esteem: physical, social, general, and cognitive competence. Maternal mental distress was examined using the general health questionnaire (GHQ) ${ }^{27}$

\section{Interviews}

Parents and children were interviewed separately at entry to the study and six monthly during the study. Areas covered by these interviews included concerns about growth and experiences of growth hormone treatment.

Concerns about growth-To assess parents' and children's concerns about growth in relation to other areas of illness and treatment we compiled a list of 11 issues identified from previous studies as being important to parents and children with renal disease (table 1).$^{28}$ For the children's interviews these 11 issues were reduced to nine.
Table 1 Issues discussed in the interviews

Current general health

Having chronic renal failure/being on dialysis/having a transplant

Treatment at home

Growth

Appearance

Coming to hospital

Child's behaviour and emotions $\dagger$

Schooling and friends

Effects of the kidney disease on the family

Future health $\ddagger$

Future prospects $\ddagger$

*Treatments other than dialysis, eg diet and medication. †Omitted from children's interviews. $\ddagger$ Combined into a single category of "concern for the future" for children's interviews.

We showed parents and older children a card describing each of these issues and engaged them in a discussion, asking them to rate on a 3 point scale their "current concern" $(0=$ no current concern about this issue; $1=$ minor concern; 2 a major concern). Potential areas of overlap were clarified by the interviewer to distinguish between the issues in the parents' and children's minds. We used pictorial representations of the issues for younger children.

After rating their level of concern for each issue, parents and children were asked to place all the issues in rank order, that is, to draw up a hierarchy of concerns.

Experiences of growth hormone treatment-We collected information about parents' and children's expectations and experiences of growth hormone treatment and any problems encountered in treatment. To inquire about treatment compliance, we asked parents and children how often they missed injections. This was recorded on a three point scale $(0=$ never miss; $1=$ miss less than once a week; $2=$ miss at least once a week). After two years, parents and children were asked to rate their overall level of satisfaction with growth hormone on a 4 point scale $(0=$ none; $1=$ slight; $2=$ marked; $3=$ extreme). They were also asked "If you could put the clock back, would you decide to have growth hormone again?".

Assessments (screening measures and interviews) were carried out regardless of whether or not the child was receiving growth hormone.

ANALYSIS

Data were analysed on the basis of intention to treat, that is, data on all patients were included regardless of growth hormone treatment status and changes in treatment for renal failure.

\section{Results}

DURATION OF GROWTH HORMONE TREATMENT AND SIDE EFFECTS

Two patients refused growth hormone treatment. Fifteen patients (50\%) discontinued growth hormone treatment during the study: six $(20 \%)$ because they received a transplant, five $(17 \%)$ because of major side effects, and four $(13 \%)$ because of poor response. Thus the duration of growth hormone treatment varied from 0 to 24 months (median 13.5 months; quartiles 7.8 and 24). Eleven patients received growth hormone for 24 months. Ten patients (36\%) experienced major or minor complications of treatment with growth hormone (table 2). 
Table 2 Growth and treatment data

\begin{tabular}{|c|c|c|c|c|c|c|c|c|c|}
\hline & \multirow{2}{*}{$\begin{array}{l}\text { Patient } \\
\text { No }\end{array}$} & \multirow{2}{*}{$\begin{array}{l}\text { Age start } \\
\text { (years) }\end{array}$} & \multicolumn{2}{|c|}{ Stage of renal failure } & \multirow{2}{*}{$\begin{array}{l}\text { Pretrial } \\
\text { Ht SD }\end{array}$} & \multirow{2}{*}{$\begin{array}{l}2 \text { Year } \\
\text { Ht SD }\end{array}$} & \multirow{2}{*}{$\begin{array}{l}\text { Height } 4 \\
\text { score }\end{array}$} & \multirow{2}{*}{$\begin{array}{l}\text { Duration } \\
\text { GH } \\
\text { (months) }\end{array}$} & \multirow[b]{2}{*}{ Comments } \\
\hline & & & Start & 2 Years & & & & & \\
\hline \multirow{11}{*}{$\begin{array}{l}\mathrm{G} \\
\mathrm{O} \\
\mathrm{O} \\
\mathrm{D}^{\star}\end{array}$} & 1 & 16.2 & Trans & Trans & -5.8 & -4.0 & 1.8 & 24 & \\
\hline & 2 & 4.5 & Pre-D & Pre-D & -2.7 & -1.0 & 1.7 & 24 & \\
\hline & 3 & 15.7 & Dial & Trans & -2.3 & -0.6 & 1.7 & 11 & Withdrawn at 11 months: transplant \\
\hline & 4 & 9.0 & Dial & Dial & -3.1 & -1.5 & 1.6 & 24 & Side effects: priapism \\
\hline & 5 & 6.8 & Pre-D & Trans & -2.9 & -1.3 & 1.6 & 8 & Withdrawn at 8 months: decreased GFR \\
\hline & 6 & 5.0 & Pre-D & Dial & -2.5 & -1.2 & 1.3 & 24 & \\
\hline & 7 & 16.4 & Trans & Trans & -4.5 & -3.2 & 1.3 & 12 & Withdrawn at 12 months: decreased GFR \\
\hline & 8 & 9.2 & Trans & Trans & -3.0 & -1.8 & 1.2 & 14 & Withdrawn at 14 months: transplant \\
\hline & 9 & 9.8 & Trans & Trans & -2.7 & -1.5 & 1.2 & 24 & \\
\hline & 10 & 4.6 & Pre-D & Pre-D & -3.5 & -2.4 & 1.1 & 24 & \\
\hline & 11 & 4.2 & Dial & Trans & -2.8 & -1.7 & 1.1 & 4 & Withdrawn at 4 months: transplant \\
\hline \multirow{9}{*}{$\begin{array}{l}\mathrm{M} \\
\mathrm{O} \\
\mathrm{D} \\
\mathrm{E} \\
\mathrm{R} \\
\mathrm{A} \\
\mathrm{T} \\
\mathrm{E}^{\star}\end{array}$} & 12 & 3.7 & Dial & Dial & -3.6 & -2.6 & 1.0 & 24 & Side effects: avascular necrosis \\
\hline & 13 & 15.5 & Dial & Dial & -4.1 & -3.4 & 0.7 & 12 & Withdrawn 1 year no response \\
\hline & 14 & 6.9 & Pre-D & Pre-D & -2.3 & -1.7 & 0.6 & 24 & \\
\hline & 15 & 9.7 & Dial & Dial & -3.0 & -2.5 & 0.5 & 24 & \\
\hline & 16 & 2.0 & Pre-D & Pre-D & -2.9 & -2.6 & 0.3 & 0 & Refused GH trial \\
\hline & 17 & 5.9 & Pre-D & Pre-D & -3.0 & -2.7 & 0.3 & 13 & Withdrawn at 13 months: small decrease GFR \\
\hline & 18 & 18.7 & Trans & Trans & -2.3 & -2.0 & 0.3 & 4 & Side effects:chest pain (patient withdrew himself) \\
\hline & 19 & 14.4 & Trans & Trans & -1.8 & -1.5 & 0.3 & 24 & \\
\hline & 20 & 4.1 & Dial & Trans & -3.7 & -3.5 & 0.2 & 7 & Withdrawn at 7 months: transplant \\
\hline & 21 & 15.2 & Trans & Trans & -4.3 & -4.3 & .0 & 12 & Side effects: minor weight gain; withdrawn $1 \mathrm{yr}$ no response \\
\hline & 22 & 13.2 & Trans & Dial & -2.8 & -2.9 & -0.1 & 24 & Side effects: small decrease GFR \\
\hline & 23 & 8.7 & Pre-D & Pre-D & -3.5 & -3.7 & -0.2 & 7 & Withdrawn at 7 months: transplant (failed) \\
\hline $\mathrm{P}$ & 24 & 4.7 & Dial & Dial & -3.0 & -3.3 & -0.3 & 15 & Withdrawn at 15 months: fits \\
\hline $\mathrm{O}$ & 25 & 11.8 & Dial & Dial & -1.9 & -2.3 & -0.4 & 3 & Withdrawn at 3 months: headaches, increase ICP \\
\hline $\mathrm{O}$ & 26 & 12.7 & Dial & Dial & -3.3 & -4.0 & -0.7 & 22 & Withdrawn at 22 months: no response \\
\hline \multirow[t]{4}{*}{$\mathrm{R}^{\star}$} & 27 & 12.7 & Dial & Dial & -1.7 & -2.6 & -0.9 & 12 & Withdrawn at 12 months: no response \\
\hline & 28 & 13.2 & Dial & Dial & -5.3 & -6.3 & -1.0 & 12 & Withdrawn at 12 months: poor response \\
\hline & 29 & 12.4 & Trans & Trans & -2.1 & -3.7 & -1.6 & 0 & Refused GH trial \\
\hline & 30 & 6.0 & Dial & Trans & -3.5 & & & 16 & Withdrawn at 16 months: transplant \\
\hline
\end{tabular}

^ Growth during the study. See methods for detail. Dial = dialysis; GFR = glomerular filtration rate; GH = growth hormone; Ht SD = height standard deviation; ICP = intracranial pressure; Pre-D = predialysis; Trans = transplant.

GROWTH RESPONSE

Height velocity was greater in the first year (mean (SD) $7.37(2.7) \mathrm{cm} /$ year; range 1.5 to 12.6) than in the second year (5.24 (2.6) $\mathrm{cm} /$ year; range 0.7 to 10.0$)$. The increase in height velocity over the pretreatment value $(4.86(2.6) \mathrm{cm} /$ year; range 1.5 to 8.5$)$ was significant at one year $(t=-5.24, \mathrm{p}<0.001)$ but not at two years $(t=-0.86, \mathrm{p}=0.39)$.

Eleven patients showed good growth during the study, nine moderate growth, and nine poor growth (table 2). Three of the patients with good growth had stopped growth hormone after a successful transplant. Patient 30 could not be measured at the end of the study as he had acquired a significant physical handicap.

The three groups had the same degree of short stature at the outset (table 3 ). The group with poor growth fell down the centiles during the study. They were less likely to continue on growth hormone after two years (0/9 $v 10 / 20$, p $=0.01$ Fisher's exact test) owing to a combination of poor response and side effects. Additional adverse features in this group were dialysis throughout the study, poorly functioning transplants, and significant physical handicap. Seven patients had one of these additional problems and two had two additional problems.

Table 3 Summary of growth data

\begin{tabular}{lll}
\hline \multirow{2}{*}{ Growth during study } & \multicolumn{2}{l}{ Height (mean SDS and range) } \\
\cline { 2 - 3 } & Outset & At 2 Years $\dagger$ \\
\hline Good $^{\star}$ & $-3.25(-2.3$ to -5.8$) \ddagger$ & $-1.84(-0.6$ to -4.0$)$ \\
Moderate $^{\star}$ & $-2.97(-1.8$ to -4.1$) \ddagger$ & $-2.5(-1.5$ to -3.5$)$ \\
Poor $^{\star}$ & $-3.14(-1.7$ to -5.3$) \ddagger$ & $-3.77(-2.3$ to -6.3$)$ \\
\hline
\end{tabular}

SDS $=$ standard deviation score. ${ }^{\star}$ See Methods for definition. $†$ Data on one patient omitted at two years because impossible to measure (see text). $¥$ No significant differences.
CHANGES IN QUESTIONNAIRE MEASURES

Parental reports of children's behaviour

No child below the age of seven years was given high scores for behavioural symptoms at any stage of the study using the BCL, and none scored above the cut off for disorder on either occasion (table 4 ).

Parent's report of behaviour in those of seven years and over (Rutter " $A$ " scores) showed a wide range (table 4) and yielded high levels of behaviour disturbance. The mean for the group as a whole was above the cut off for potential psychiatric disturbance throughout. There was no association between Rutter " $A$ " score and renal status or growth hormone treatment.

Parents were asked about changes in their child's behaviour. Few major changes were reported; when they were mentioned they were seldom attributed directly to growth hormone treatment, and reports were divided almost equally between positive and negative changes.

\section{The moods and feelings questionnaire}

There was wide variation in the range of children's scores for depression at the start and after two years with no differences in the means (table 4). As well as the 13 children who completed the MFQ at the start and at two years (table 4), two additional children completed the inventory at two years. Different cut offs to indicate clinical depressive disorder have been used for different sexes and different age groups with this questionnaire, ${ }^{24}$ but using a cut off of 27 for the whole group of 10-19 year olds, two $(14 \%)$ were above this threshold at the outset and four (28\%) after two years. Four children were above cut off at two years (one had scored above threshold at both times, one 
Table 4 Psychological effects: questionnaire measures (questionnaire scores for patients observed twice (at start and at two years)

\begin{tabular}{|c|c|c|}
\hline Measure & Start & 2 Years \\
\hline \multicolumn{3}{|c|}{ Depression (MFQ: 10 years + ), $n=13$} \\
\hline Range & 3 to 28 & 2 to 36 \\
\hline Mean (SD) & $17(9.1)$ & $17(11.2)$ \\
\hline Score $27+$ & $2(15 \%)$ & $2(15 \%)$ \\
\hline \multicolumn{3}{|c|}{ Self esteem (Harter: 10 years + ), $n=12$} \\
\hline \multicolumn{3}{|c|}{ Cognitive subscale } \\
\hline Range & 11 to 28 & 10 to 22 \\
\hline Mean (SD) & $18.5(5.0)$ & $17.5(4.2)$ \\
\hline \multicolumn{3}{|l|}{ Social subscale } \\
\hline Range & 14 to 28 & 17 to 28 \\
\hline Mean (SD) & $21.91(4.2)$ & $22.16(3.6)$ \\
\hline \multicolumn{3}{|l|}{ Physical subscale } \\
\hline Range & 11 to 28 & 14 to 24 \\
\hline Mean (SD) & $19.25(5.7)$ & $17.66(2.7)$ \\
\hline \multicolumn{3}{|l|}{ General subscale } \\
\hline Range & 16 to 28 & 14 to 26 \\
\hline Mean (SD) & $21.91(4.2)$ & $20.4(3.3)$ \\
\hline \multicolumn{3}{|c|}{ Behaviour (BCL: $<7$ years), $n=9$} \\
\hline Range & 3 to 11 & 2 to 11 \\
\hline Mean (SD) & $7.44(2.9)$ & $6.33(3.1)$ \\
\hline Score $12+$ & 0 & 0 \\
\hline \multicolumn{3}{|c|}{ Behaviour (Rutter A: 7 years + ), $n=12$} \\
\hline Range & 4 to 32 & 6 to 30 \\
\hline Mean (SD) & $14.25(8.0)$ & $14.58(7.6)$ \\
\hline Score $13+$ & $7(58 \%)$ & $5(42 \%)$ \\
\hline \multicolumn{3}{|c|}{ Mother's mental distress (GHQ), $n=19$} \\
\hline Mean (SD) & $2.05(3.1)$ & $4.15(4.7)$ \\
\hline Score above cut off $(>5)$ & $4(21 \%)$ & $8(42 \%)$ \\
\hline
\end{tabular}

Harter self esteem subscales: comparison scores for local 11 to 16 year olds (mean (SD)): Cognitive subscale: 20.8 (3.85) Social subscale: 22.9 (3.22) Physical subscale: 20.9 (4.97) General subscale: $22.5(3.43)$

only at two years, and the two additional patients also scored above threshold). Three of the four patients with high scores at two years had grown poorly (3/4 v 1/11, Fisher's exact test, $\mathrm{p}=0.03)$.

\section{Harter questionnaires}

The four subscales of self esteem showed very wide variations in scoring and included one child who on the first occasion gained the maximum score on every item, indicating that she perceived herself as more competent than her peers on all 28 items of the scale. Despite this one unusually high set of scores in this very small sample, the mean scores on each subscale were in every case lower than the means for healthy local 11-16 year olds. ${ }^{29}$ These differences were not statistically significant. After two years the range of scores continued to be wide. Self rating for social competence remained constant, but the mean scores for the other items fell. The decrease was not statistically significant for the 12 children who completed questionnaires on both occasions.

Table 5 Changes in children's growth concern score during the study

\begin{tabular}{lll}
\hline & \multicolumn{2}{l}{ Growth during study } \\
\cline { 2 - 3 } Change in growth concern score & Poor & Good/moderate \\
\hline +2 (increase from no concern to major concern) & 1 & 0 \\
0 (unchanged growth concern) & 3 & 2 \\
- (reduced concern from major to minor or minor to & 2 & 5 \\
none) &
\end{tabular}

No patients had other possible scores of +1 or -2 .

$\star$ Change in concern significantly related to change in standard deviation score at two years $(\mathrm{p}=$ 0.015 , Spearman's rank correlation).
Maternal general health questionnaire

Mothers' scores of mental distress increased between the start of the study and the two year follow up indicating greater distress overall (mean $t$ value at outset $=2.1$, at two years 3.62, $\mathrm{p}=0.03)$. There was no association between mothers' mental distress scores and the child's age or stage of renal failure management. The number of mothers scoring above a cut off point $(5+)$ indicating potential psychiatric disorder increased from $4(13 \%)$ to $8(27 \%)$ during the study: this was not statistically significant (McNemar's test, $\chi^{2}=1.125, \mathrm{p}=0.28$ ). Scores above the cut off at the end of the study were more common in mothers of children who had grown poorly (poor growth mothers $4 / 10$, good/moderate growth mothers $4 / 20$ : Fisher's exact test, $p=0.38$ ).

GROWTH CONCERNS

Parental growth concerns

At the start, nine of 30 parents (30\%) scored growth as a major concern (score 2) but this proportion decreased to five of $29(17 \%)$ at two years $(\mathrm{z}=-2.21 ; \mathrm{p}=0.02$; Wilcoxon signed rank test). There was no association between scores for parental concern about growth at outset and at two years and child's age, sex, height SDS, or $\triangle$ SDS. The proportion showing decrease in concern was not significantly different in the three growth groups ( $4 / 9$ poor, $3 / 9$ moderate, $5 / 11$ good).

The ranking also confirmed the reduction in parental concern about growth. Major concern about growth was the fourth commonest major concern at the start of the trial but declined in relative importance at two years, when it was the seventh ranked concern (Wilcoxon signed rank test: $\mathrm{z}=-3.10, \mathrm{p}=0.001$ ). Worries about their child's future health and future prospects were first and second ranked concerns at the start and at two years.

Children's and adolescents' growth concern scores Thirteen subjects were able to complete the whole interview at the beginning and after two years. At the outset, three of $13(23 \%)$ had major concerns about growth, compared with one of $13(8 \%)$ at two years. This decrease was not statistically significant (McNemar's test, $\chi^{2}$ $=0.25, \mathrm{p}=0.62)$. However, the one patient showing major concern at two years had reported no concern about growth at the outset and had grown poorly. Overall the changes in children's concern about growth (table 5) were associated with $\Delta$ SDS $\left(r_{s}=-0.61, \mathrm{p}=0.025\right.$, Spearman's rank correlation test) but not with height SDS at the end of the study $\left(r_{s}=-0.24\right.$, $\mathrm{p}=0.43$, Spearman's rank correlation test).

There were no significant changes in the ranking order of children's concerns about growth during the course of the study.

\section{EXPERIENCES OF GROWTH HORMONE TREATMENT} Giving injections

The proportion of children who participated in giving their growth hormone injections declined during the course of treatment. After six months nearly one third $(7 / 22)$ of the children receiving growth hormone were reported as 
giving their own injections and a further six $(27 \%)$ undertook the procedure with a parent. At one year, 31\% (5/16) were giving their own injections and $19 \%$ (3/16) participated with their parents. At two years, only one of the 12 children who were still receiving growth hormone-one had received growth hormone treatment for one year and 11 for two years - was giving his own injections, four $(33 \%)$ had their parents' help, and in seven cases $(58 \%)$ parents were assuming full responsibility for treatment.

Parents and children were asked at interview about any difficulties they encountered with injections or other aspects of treatment. At one year, $69 \%(11 / 16)$ reported some problems with treatment. In nine cases these were minor (for example, pain at the injection site or the inconvenience of daily injections). Major problems were reported in two cases: bleeding and bruising in one patient and marked behavioural difficulties, including screaming and crying, in a 14 year old boy. By the two year review, minor problems were reported by all parents of the 12 children still receiving growth hormone. These included parental exasperation at "having one more thing to do," difficulties persuading children to vary the injection site, and children who complained regularly about the injection.

\section{Adherence to treatment}

After one year's treatment, seven of 17 parents $(41 \%)$ reported non-compliance (six reported missing injections "sometimes", and one reported missing "often"). Parental reports of non-compliance were obtained at one and two years in all 11 patients who received growth hormone for two years. One parent $(9 \%)$ reported no missed injections at any time. In the remaining 10 children, four $(37 \%)$ reported missing injections at one year, and all 10 $(91 \%)$ at two years (nine missed injections "sometimes" and one "often"). This increase in non-compliance was significant $(\mathrm{McNe}-$ mar's test, $\left.\chi^{2}=5.1, p=0.02\right)$. There was a wide variation in the reasons given. These included occasionally forgetting injections or taking a flexible approach to treatment, for example missing occasional injections for social convenience. More serious problems were reported for several patients, including two adolescents, whose non-compliance lasted for several weeks at a time; in one of these this was part of a total refusal to take any treatment. In two cases noncompliance was the reason given by paediatricians for stopping prescription of growth hormone.

Seven of the children (aged 9 to 17 years) who were receiving growth hormone at the end of the study were old enough to report on their own non-compliance. All reported missing injections (four missed "often," three missed "sometimes"). There were no correlations between parents' or children's reports of non-compliance and physical measures including height SDS and $\triangle$ SDS, or with children's or parents' concerns about growth or behaviour scores.
Satisfaction with growth hormone

Twenty of 27 parents (74\%) reported satisfaction with growth hormone. Additionally 24 of 27 parents $(89 \%)$, in response to the question "If you could put the clock back...?", would opt for growth hormone treatment for their children again. Neither finding was associated with height SDS or $\triangle$ SDS. (Two parents refused growth hormone treatment and these questions were not relevant to patient 30 at two years.)

Overall, children expressed less satisfaction with growth hormone than parents (five of 14 $(38 \%) v 20$ of $27(74 \%)$ ) and there was no correlation between parents' and children's levels of satisfaction using the 1-4 ranking (Spearman's rank correlation coefficient $=0.25$, NS). For 14 patients reports of satisfaction were available from both parent and child. Only one child $(7 \%)$ expressed satisfaction with growth hormone when his parents were dissatisfied (he had grown well and both he and his parents would opt for growth hormone again). In nine $(64 \%)$, parent and child responses agreed (five (36\%) were both satisfied and four $(29 \%)$ were both dissatisfied), and four parents (29\%) expressed satisfaction while their children were dissatisfied. These differences are not associated (McNemar's test, $\chi^{2}=0.8, p=0.37$ ).

Children were less likely to opt for growth hormone treatment again than were their parents. In one of 14 cases $(7 \%)$, both parents and child said they would not opt for growth hormone again. In the remaining 13 cases, all the parents would opt for growth hormone again but only seven of the children. Children are significantly less likely to opt for growth hormone again than their parents (McNemar's test, $\left.\chi^{2}=4.2, \mathrm{p}=0.02\right)$. Unlike their parents, children's answers to this question were related to growth response. No child (out of five) who responded poorly to growth hormone ( $\Delta$ SDS $\leqslant 0$ ) would opt for growth hormone again, while two of five $(40 \%)$ with moderate growth response $(\triangle$ SDS $0 \leqslant 1)$ and four of five $(80 \%)$ with good growth $(\Delta S D S>1)$ would do so. There was a significant association between children's decision to opt for growth hormone again and $\triangle$ SDS (Mann-Whitney $\mathrm{U}$ statistic $=$ $1.5, p=0.0006)$

\section{Discussion}

We carried out this study at a critical time when growth hormone was just beginning to be offered as a routine option. The benefits and risks of growth hormone in chronic renal failure were not well established. The problems this posed in recruitment to these studies have already been reported. ${ }^{20}$ It was important, therefore, to study the impact of raising the possibility of improved growth with very short children and to document the psychological consequences in all circumstances (treatment successes, treatment failures, and those who refused growth hormone).

Inevitably the small numbers limit the conclusions from this study. The possible gender bias is another limitation. Renal failure is commoner in boys than in girls; growth is also poorer in boys with renal failure..$^{30-33}$ These fac- 
tors partly explain the male preponderance in our study (6.5:1) but given the greater social importance attached to height in boys it is possible that there was some gender bias in the recruitment process. Two further limitations are the wide range of developmental levels and inclusion of patients at different stages of chronic renal failure. Despite these problems, we can draw robust conclusions from the study, and as the response to treatment ( 21 patients, $66 \%$ ), incidence of side effects (10 patients, $36 \%$ ), and drop out rate (11 patients, $43 \%$ ) are almost identical to previous studies, ${ }^{4-11}$ the results of the psychological study are likely to be generalisable.

This study shows that even when patients are selected because they are short, and in the context of treatment trials, short stature has a lower priority than other issues in the minds of parents and children with renal failure. This is reassuring evidence of proper priority setting. Parents also showed a significant reduction in concern about growth during the period of the study. It is possible that the levels of concern about growth were artificially increased at the start of the trial-because of the attention focused at the time on the new possibility of growth hormone treatment-and that concern returned to pretreatment levels as the study proceeded. We believe a more likely explanation is that intervention resulted in a genuine lowering of concern, but only a replication of the study could answer this question definitively. The absence of association between height SDS or improvement of growth during the study ( $\triangle$ SDS) and level of concern about growth, the finding of high levels of parental satisfaction with growth hormone treatment (independent of growth outcome), and the large percentage of parents who would "try growth hormone again" (again independent of growth outcome) suggest that this reduction in concern was related to the use of growth hormone treatment rather than to any objective measure of success. However, our finding that parents have a high level of satisfaction - and that their level of concern falls whether or not their child grows well-means that other risks need to be considered. For example, treatment may be requested without a real indication that it could lead to better growth. This would be expensive for the NHS and demanding of children and parents. Careful auxological assessment is therefore crucial, and there is a need to agree treatment objectives with parents and children at the outset of treatment.

Overall, children's concern about growth decreased, but not significantly. Their reduction in growth concern and their satisfaction with treatment, however, were related to the improvement in growth during the study ( $\triangle$ SDS). Children's satisfaction with growth hormone treatment was less than their parents and fewer would opt for treatment again. This latter finding was also significantly related to the $\triangle$ SDS. These responses are consistent: children who grow well with treatment are satisfied with treatment, would opt for it again, and their concern about growth decreases.
Maternal mental distress, as assessed by the GHQ, increased during the study, and there was a non-significant increase in "cases" at two years. More of the patients who failed to respond to growth hormone were on dialysis; maternal psychological problems have been found to be more prevalent in parents of children at this stage of renal failure management. ${ }^{17}$ Some of the other disabilities in this group of children with poor growth have already been detailed. Thus they had a severe and demanding illness which was likely to have been very stressful for their mothers. As growth hormone treatment resulted in more work for the parents (parents of those still on growth hormone at the end of the study having largely taken over responsibility for giving yet another drug, this one by injection), this reinforces the need for support for parents (whether from professionals, groups, or families). There is also a need for professionals to be alert to presentations of mental distress in order to encourage vigorous treatment. Not only should treatment of depressive symptoms be encouraged, but any relation between parental functioning and treatment demands should be kept under review, and carefully considered alongside the measured success or otherwise of the growth hormone treatment.

The depression inventory which we used has now been found to have acceptable statistical properties when examining populations of depressed or potentially depressed children. ${ }^{24}$ There was an association between scores above cut off at two years and poor growth during the study, and this was statistically significant. This result was influenced by the scores of two children who only completed the inventory at the end of the study, so we should be cautious about assuming that this significant finding is related to poor growth alone.

In three of the four subscores of the Harter scale, children's self esteem scores were lower than those of healthy local children and this gap increased with time. These differences were not statistically significant (there are small numbers, wide variation in the scores, and bias introduced by the one child who scored maximum on all 28 items of the questionnaire). This should not obscure the fact that several children perceived themselves-we believe accurately - to be performing very poorly compared with their peers in physical, cognitive, and general spheres. The differences between these subscale findings and that for the social subscale (which does not change and is not different from that of healthy local children) suggests children make accurate distinctions between areas of competence. Sinnema and colleagues also found that among a group of 20 adolescent transplant patients receiving growth hormone, scores for self esteem (using the Rosenberg global scale) were significantly below the population mean. However, they reported minor but non-significant improvements in self esteem, anxiety, and depression after two years of treatment with growth hormone, although the mean scores remained below the population mean at the end of the study. ${ }^{16}$ Their study differs in a number of 
respects from ours, in that only transplant patients were studied and the results were not analysed on the basis of intention to treat. This is important as there were four patients who were not studied after two years and of these three had lost their transplants: in other words we are concerned that those lost to follow up were a more vulnerable group in terms of self esteem. It is not surprising to discover that, whatever the true picture of the direction of scores (particularly when using different instruments) and whether or not it produces good physical results, growth hormone is no universal panacea for self esteem in children with chronic renal failure. As in short children without chronic renal failure, it is highly likely that children's psychological state is not dependent on any single variable. ${ }^{34}$

Parents' reports of behaviour in children of seven years and older were comparable with those in existing studies of chronic renal failure patients. ${ }^{18}$ There was a small but nonsignificant fall in scores over the study period. This also suggests that growth hormone trials had no particular adverse or positive impact on psychiatric adjustment. We cannot explain the surprising difference in parental reports of behavioural symptoms below and above seven years of age, but perhaps parents tolerate a greater range of responses as being "normal" when children are younger and have adjusted their expectations.

Another result of this study was to identify the burdens of, and barriers to, treatment - an analysis which helps to maximise benefits. One such barrier to successful treatment is noncompliance. There is one report of no difficulty with injections in chronic renal failure, ${ }^{16}$ but other investigators, ${ }^{35}$ like us, also found this to be a significant issue in non-chronic renal failure patients. In our study, intermittent noncompliance was reported in $91 \%$ of subjects at two years, and we documented a significant increase between the first and second year. The increasing proportion of parents who reported giving the injections was probably a result of the children's reluctance and parental attempts to prevent missed treatment. Non-compliance led to withdrawal from treatment even on occasions when the growth response had been good. At the outset of our study we showed that parents and children had a good understanding of the issues involved in growth hormone treatment. ${ }^{20}$ We therefore think it unlikely that poor understanding is the explanation of noncompliance in our study. It may be tempting to withdraw treatment when injections are missed, but data on the extent to which treatment is taken conscientiously are scanty. The evidence is that treatment compliance is limited even for immunosuppressive regimes after renal transplantation. ${ }^{36-38}$ The decision to withdraw or prescribe growth hormone in chronic renal failure should be made in open discussions with children and parents, information about the physical results for the individual child being reviewed alongside the difficulty of giving the treatment, the burden it places on parent and child, the context of other treatments and their importance, and the psychological health and social supports of all family members at the time. Further studies should examine prospectively different methods of supporting families in giving treatment, and of preparing them to cope with the demands of the illness at different developmental and illness stages.

We have highlighted a group of children who had linked physical and psychological vulnerability. They maintained or increased their concern about growth in parallel with their failure to respond to growth hormone treatment. They also showed a trend towards more depression, lower self esteem, and more maternal mental distress. Our study design does not allow us to conclude that disappointment about poor growth made adjustment even more difficult for these children and their families. This reinforces the need for further longitudinal studies with enough subjects with poor growth to explore these difficulties more precisely and to examine factors which ameliorate poor psychological outcomes.

We conclude that no additional costs to the psychological health of the children occurred as a result of the availability of treatment with growth hormone. Intensive feeding programmes, dialysis schedules, timing of transplantation, and post-transplant immunosuppressive regimens have all been modelled to maximise growth. Despite the optimal use of these treatments, many children with renal failure remain very short $(37 \%$ of patients in this study had heights between two and three standard deviations below the mean for age, and in a further $54 \%$ the height was more than three standard deviations below the mean). Since this study was begun several reports have shown growth hormone treatment to be effective in chronic renal failure. ${ }^{4-11}$ We strongly support using growth hormone to further improve the growth of children with chronic renal failure. We do not believe that it is necessary to demonstrate short term psychological benefit in order to justify growth hormone treatment in renal failure; the indications for treatment are securely grounded in the fact that there is an underlying disorder associated with a variety of physical and physiological abnormalities which are corrected (partially or completely) by treatment. ${ }^{39}$ Additionally, studies such as ours, by identifying difficulties with treatment, should maximise the benefit of treatment and highlight the special needs of the small number of children who fail to respond.

We thank the parents and children who took part in this study, and Mrs S Marland for her secretarial help. The research would Pharmacia \& Upjohn. We are also grateful to the following peoPharmacia \& Upjohn. We are also grateful to the following peo-
ple, without whose help and collaboration the study would not have been possible: Dr J Evans, Dr M Lewis, and Sister J Willock (Royal Manchester Children's Hospital); Dr D Milford, Mrs C Hawkins, and Dr L Winkley (Birmingham Children's Hospital); Dr L Rees, Dr H Maxwell, Mrs S Madden, and Sister R O'Sullivan (Royal Free Hospital); Dr T Brocklebank and Sister C Pendlebury (St James's Hospital, Leeds).

1 Fine RN. Pathophysiology of growth retardation in children with chronic renal failure. F Pediatr Endocrinol 1994;7:7983.

2 Schaefer F, Mehls O. Endocrine, metabolic and growth disorders. In: Holliday MA, Barratt TM, Avner ED, eds. Pediatric nephrology. 3rd Ed. Baltimore: Williams and Wilkins, 1994:1241-86. 
3 Mehls O, Ritz E. Skeletal growth in experimental uremia. Kidney Int 1983;24(suppl 15):S53-62.

4 Hokken-Kols Schrama SMPF, et al. Placebo-controlled, double-blind, cross-over trial of growth hormone treatment in prepubertal children with chronic renal failure. Lancet 1991;338 585-90.

5 Fine RN, Kohaut EC, Brown D, Perlman AJ. Growth afte recombinant human growth hormone treatment in children with chronic renal failure: report of a multicenter randomized double-blind placebo-controlled study. F Pediat 1994;124:374-82.

6 Mehls O, Broyer M. Growth response to recombinant human growth hormone in short prepubertal children with chronic renal failure with or without dialysis. Acta Paediat Suppl 1994;399:81-7.

7 Maxwell H, Rees L. Recombinant human growth hormone in infants with chronic renal failure. Arch Dis Child in infants with

8 Wuhl E, Haffner D, Nissel R, et al. Short dialyzed children respond less to growth hormone than patients prior to dialysis. Pediatr Nephrol 1996;10:294-8.

9 Hokken-Koelega ACS, Stijnen T, De Jong RCJW, et al. A placebo-controlled double-blind trial of growth hormone treatment in prepubertal children after renal transplant. Kidney Int 1996;49(suppl 53):S128-34.

10 Fine RN, Kohaut E, Brown D, et al. Long-term treatment of growth-retarded children with chronic renal insufficiency with recombinant growth hormone. Kidney Int 1996;49: $781-5$.

11 Ito $\mathrm{K}$, Kawaguchi $\mathrm{H}$, and the Japanese Multi-Center Open Study Group on Children with Renal Disease. Treatment of uremic children in Japan with recombinant human growth hormone (rhGH). $\mathcal{F}$ Pediatr Endocrinol 1994;7:11518 .

12 Scarth LG, Gardiner HM. By taking thought: studies of treated short normal children. In: Stabler B, Underwood LE, eds. Growth, stature, and adaptation. Chapel Hill: LE, eds. Growth, stature, and adaptation.

13 Frisch H, Hausler G, Lindenbauer S, Singer S. Psychological aspects in children and adolescents with hypopituitarcal aspects in children and adolescents with
ism. Acta Paediatr Scand 1990;79:644-51.

14 Kusalic $M$, Fortin C. Growth hormone treatment in hypopituitary dwarfs. Can Psychiatr Assoc $\mathcal{F}$ 1975;20:32531.

15 Rotnem D, Cohen DJ, Hintz RL, Genel M. Psychological sequelae of relative "treatment failure" for children receiving human growth hormone replacement. F Am Acad Child Psychiatry 1979;19:505-20.

16 Sinnema G, Akkerhuis GW, Hulstijn-Dirkmaat GM, et al. Psychosocial effects of two years of growth hormone treatment in adolescents with short stature. In: Koelega $\mathrm{H}$, ed. Growth failure in children with renal disease. Rotterdam: Academisch Proefschrift, 1994:143-51.

17 Reynolds JM, Garralda ME, Jameson RA, Postlethwaite RJ. How parents and families cope with chronic renal failure. Arch Dis Child 1988;63:821-6.

18 Garralda ME, Jameson RA, Reynolds JM, Postlethwaite RJ Psychiatric adjustment in children with chronic renal Psychiatric adjustment in children with chro
failure. 7 Child Psychol Psychiatry 1988;29:79-90.

19 Reynolds JM, Wood AJ, Eminson DM, Postlethwaite RJ. Short stature and chronic renal failure; what concerns children and parents? Arch Dis Child 1995;73:36-42.
20 Postlethwaite RJ, Reynolds JM, Wood AJ, Eminson DM. Recruiting patients to clinical trials: lessons from studies of
growth hormone treatment in renal failure. Arch Dis Child 1995; 73:30-5.

21 Richman N, Stevenson J, Graham P. Pre-school to school; a behavioural study. London: Academic Press, 1982.

22 Rutter M, Tizard J, Whitmore K, eds. Education, health and behaviour. London: Longman, 1970.

23 Costello EJ, Angold A. Scales to assess child and adolescent depression; checklists, screens and nets. F Am Acad Child Psychiatry 1988;27:726-34.

24 Wood A, Kroll L, Moore A, Harrington R. Properties of the moods and feelings questionnaire in adolescent psychiatric
outpatients: a research note. $\mathcal{F}$ Child Psychol Psychiatry outpatients: a resea

25 Harter S. The perceived competence scale for children. Child Dev 1982;53:87-97.

26 Hoare P, Elton R, Greer A, Kerley S. The modification and standardisation of the Harter self-esteem questionnaire with Scottish school children. Eur Child Adolescent Psychiatry 1993;2:19-33.

27 Goldberg D, Hillier VF. A scaled version of the general health questionnaire. Psychol Med 1979;9:139-45.

28 Reynolds JM, Garralda ME, Jameson RA, Postlethwaite RJ. Living with chronic renal failure. Child Care Health Dev 1986;12:401-7.

29 Shortall DA. An epidemiological survey of physical symptoms in an adolescent population. Manchester: University of Manchester, 1995. (MSc thesis.)

30 Goh D, Evans JHC, Houston IB, et al. The changing pattern of children's dialysis and transplantation over 20 years. Clin Nephrol 1994;42:227-31.

31 Rizzoni G, Ehrich JHH, Brunner FP, et al. Combined report on regular dialysis and transplantation of children in Europe, 1988. Nephrol Dial Transplant 1989;4(suppl 4):3140.

32 Kohaut EC, Tejani A. The 1994 annual report of the North American Pediatric Renal Transplant Cooperative Study. Pediatr Nephrol 1996;10:422-34.

33 Warady BA, Hebert D, Sullivan EK, et al. Renal transplantation, chronic dialysis, and chronic renal insufficiency in children and adolescents. The 1995 Annual Report of the North American Pediatric Renal Transplant Cooperative Study. Pediatr Nephrol 1997;11:49-64.

34 Downie AB, Mulligan J, Stratford RJ, et al. Are short normal children at a disadvantage? The Wessex Growth Study. BMF 1997;314:97-100.

35 Smith SL, Hindmarsh PC, Brook CGD. Compliance with growth hormone treatment - are they getting it? Arch Dis Child 1993;68:91-3.

36 Beck DE, Fennell RS, Yost RL, et al. Evaluation of an educational program on compliance with medication regimens in pediatric patients with renal transplants. $f$ Pediatr 1980;96:1094-7.

37 Ettenger RB, Rosenthal JT, Marik JL, et al. Improved cadaveric renal transplant outcome in children. Pediatr Nephrol 1991;5:137-42.

38 Gagnadoux MF, Niaudet P, Broyer M. Non-immunological risk factors in pediatric renal transplantation. Pediatr Nephrol 1993;7:89-95.

39 Voss LD, Wiklund I. Short stature and psychosocial assessment. Acta Paediatr 1995;suppl 411:69-74. 